ORIGINAL ARTICLE

\title{
Does the presence of an implant including expander with internal port alter radiation dose? An ex vivo model
}

\author{
Barbara Strang MD ${ }^{1}$, Kyla Murphy $\mathrm{RT}^{2}$, Shane Seal $\mathrm{MD}^{3}$, Arianna Dal Cin MD ${ }^{1,3}$
}

\begin{abstract}
B Strang, K Murphy, S Seal, A Dal Cin. Does the presence of an implant including expander with internal port alter radiation dose? An ex vivo model. Can J Plast Surg 2013;21(1):37-40.
\end{abstract}

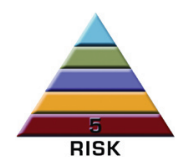

BACKGROUND: There is a lack of literature examining the dosimetric implications of irradiating breast implants and expanders with internal ports inserted at the time of mastectomy.

OBJECTIVE: To determine whether the presence of breast expanders with port in saline or silicone implants affect the dose uniformity across the breast when irradiated with various photon and electron energies.

METHODS: One tissue-equivalent torso phantom with overlying tissue expanders in saline or silicone implants were irradiated using tangential fields with $6 \mathrm{MV}$ and $18 \mathrm{MV}$ photons and $9 \mathrm{MeV}$ and $12 \mathrm{MeV}$ electrons. All dose measurements were performed using thermoluminescent dosimeters (TLDs). The TLDs were arranged around the port and the perimeters of either the expander, or saline or silicone implant. Comparisons of measured radiation doses, and between the expected and measured doses of radiation from the TLDs on each prosthesis, were performed. Data were analyzed using two-tailed $t$ tests.

RESULTS: There were no differences in TLD measurements between the expander and the saline implant for all energy modalities, and for the expected versus actual measurements for the saline implant. Higher than anticipated measurements were recorded for a significant number of TLD positions around the silicone implants.

CONCLUSIONS: Radiation doses around saline implants or expanders with internal port were unaltered, whereas dose recordings for silicone implants were higher than predicted in the present laboratory/ex vivo study.

Key Words: Dosimetry; Implants; Radiation

\section{La présence d'un implant comprenant un expandeur à port interne modifie-t-elle la dose de radiation? Un modèle ex vivo}

HISTORIQUE : Peu de publications portent sur les conséquences dosimétriques de la radiation d'implants mammaires et d'expandeurs à port interne insérés au moment de la mastectomie.

OBJECTIF : Déterminer si la présence d'expandeurs mammaires à port dans des implants remplis de solution saline ou de gel de silicone nuit à l'uniformité de la dose de diverses énergies de photons et d'électrons irradiée sur le sein.

MÉTHODOLOGIE : Les chercheurs ont utilisé un fantôme thoracique équivalant au tissu pourvu d'implants remplis de solution saline ou de gel de silicone avec expandeur et l'ont irradié de champs tangentiels à photons de $6 \mathrm{MV}$ et $18 \mathrm{MV}$ et à électrons de $9 \mathrm{MeV}$ et $12 \mathrm{MeV}$. Ils ont mesuré toutes les doses à l'aide de dosimètres thermoluminescents (DTL). Ces DTL étaient placés autour du port et des périmètres de l'expandeur ou de l'implant rempli de solution saline ou de gel de silicone. Ils ont comparé les doses de radiation mesurées, ainsi que les doses de radiation prévues par rapport aux doses mesurées à l'aide des DTL sur chaque prothèse. Ils ont analysé les données à l'aide de deux tests $t$ bilatéraux.

RÉSULTATS : Les chercheurs n'ont constaté aucune différence entre l'expandeur et l'implant rempli de solution saline et entre les mesures prévues et réelles de l'implant rempli de solution saline pour ce qui est des modalités d'énergie dans les mesures de DTL. Ils ont obtenu des mesures plus élevées que prévu à l'égard de nombreuses positions des DTL autour des implants remplis de gel de silicone.

CONCLUSIONS : Les doses de radiation autour des implants remplis de solution saline ou des expandeurs à port interne ne changeaient pas, tandis que les doses enregistrées pour les implants remplis de gel de silicone étaient plus élevées que prévu dans la présente étude de laboratoire ex vivo.

assessing the value and toxicity of locoregional radiotherapy $(4,5)$, the indications for postmastectomy chest wall radiation now routinely include tumour size $>5 \mathrm{~cm}$, positive surgical resection margins, heavy node positivity, locally advanced breast cancer and recurrent cancer $(6,7)$. In many jurisdictions, these indications have expanded to consider all node-positive breast cancers $(7,8)$. As a result, unresolved issues surrounding the irradiation of the chest wall containing a postmastectomy implant or expander require urgent attention as the number of patients undergoing this treatment increases.

When reconstruction using an implant is planned, a tissue expander is most commonly placed subpectorally at the time of mastectomy. At a later date, it is replaced with a permanent saline or silicone implant. The expander is injected with saline at this time and subsequently at regular intervals to sufficiently expand the skin and soft tissues of the chest wall to accommodate the permanent implant. Tissue expansion can be performed via an external or internal port. The internal port of an expander has a circular metal base $3 \mathrm{~cm}$ in diameter that prevents the needle from passing through the port and puncturing the expander or passing into the chest wall. The port contains a rare-earth magnet that is used to localize the port from the surface of the overlying skin for each injection. Therefore, chest wall 


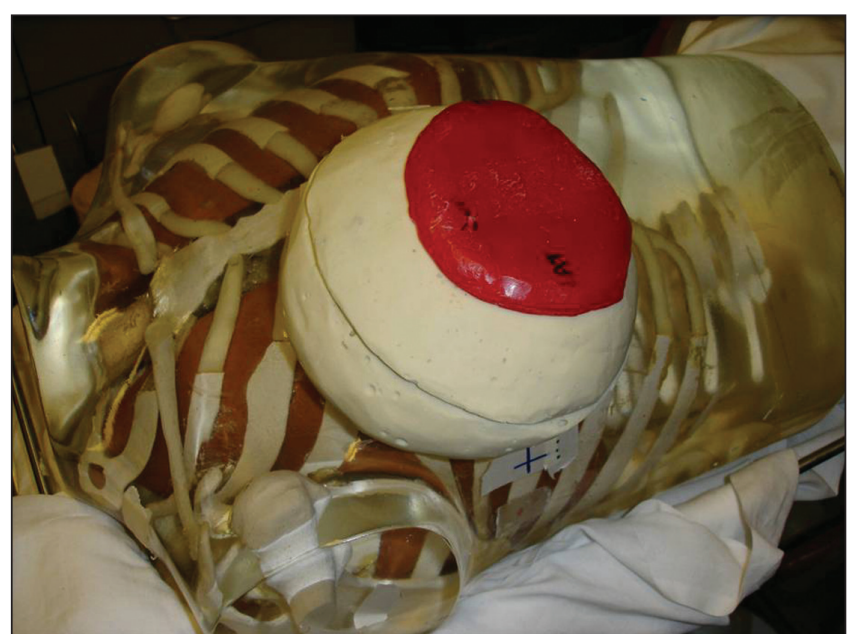

Figure 1) The phantom torso with prosthesis

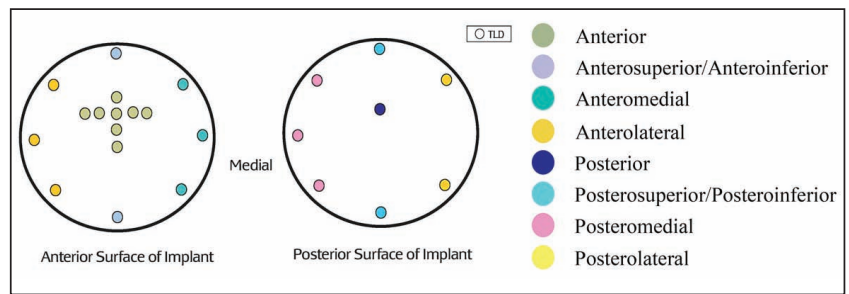

Figure 2) Location of thermoluminescent dosimeters (TLD) placed on the anterior and posterior surfaces of the tissue expander or implant

irradiation in which an implant is used for reconstruction will involve either irradiating the expander with the metallic port and magnet in situ or, if radiotherapy is delayed, irradiating the permanent implant. The presence of the port raises concern about dose pertubations around the port that could contribute to either underdosing with potential for loss of tumour control or overdosing with potential for increasing toxicity, including reconstruction failure. The rate of reconstruction failure increases following irradiation of breast implants, usually resulting from the formation of a fibrous capsule around the implant causing capsular contracture. Failure can also be caused by increases in infection, implant exposure and extrusion due to delayed wound healing. Whether this is partly a result of increased dose to the tissue adjacent to the implant is not clear and has not been studied.

The purpose of the present study was to determine whether the radiation dose to the chest wall in the setting of postmastectomy radiotherapy is altered by the presence of a tissue expander or by a saline or silicone implant. Ultimately, we developed an ex vivo model to determine whether it is safe to irradiate a patient's chest wall that contains an expander or implant.

\section{METHODS}

To mimic a breast reconstruction after mastectomy, a breast-shaped phantom was constructed using Jeltrate (Dentsply International, USA), a powdered substance that, when mixed with water, forms a tissueequivalent bolus material (9). A saline-filled expander (600 mL saline), an identically shaped saline implant $(600 \mathrm{~mL}$ without a port) or a silicone permanent implant $(540 \mathrm{~mL}$ model without a port) were placed in the phantom, which consisted of a $1 \mathrm{~cm}$ thickness of Jeltrate to mimic skin, subcutaneous tissue and muscle (Figure 1). The prostheses selected had equivalent dimensions including projection. When the expander (with port) was used, it was positioned in the phantom with the metallic port lying anteriorly, similar to its position in a chest wall reconstruction. A total of 24 thermoluminescent dosimeters (TLDs) (10) were placed on both the anterior and posterior surfaces of the expanders and implants to measure radiation dose (Figure 2). For

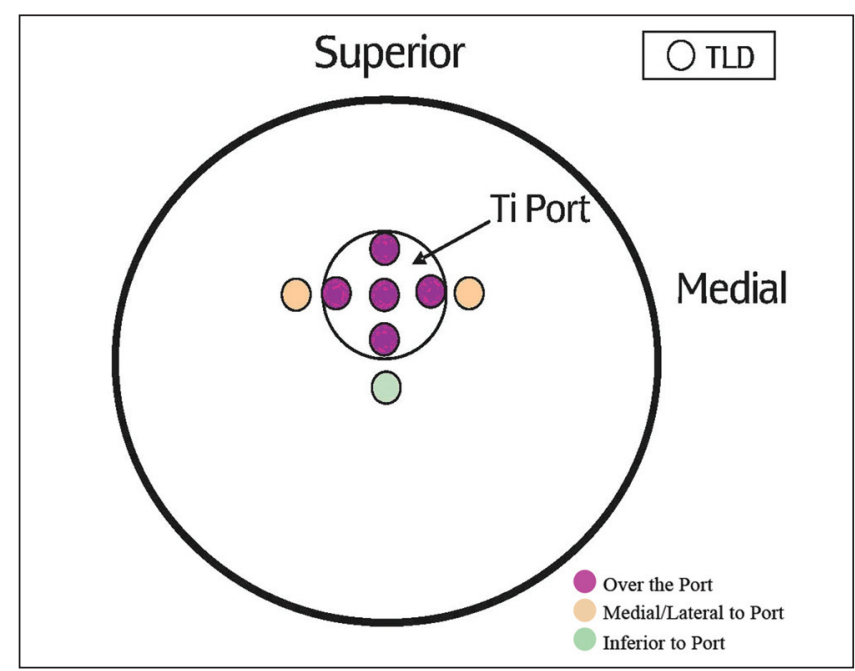

Figure 3) Thermoluminescent dosimeter (TLD) placement over the metal port of the breast expander. Ti Titanium
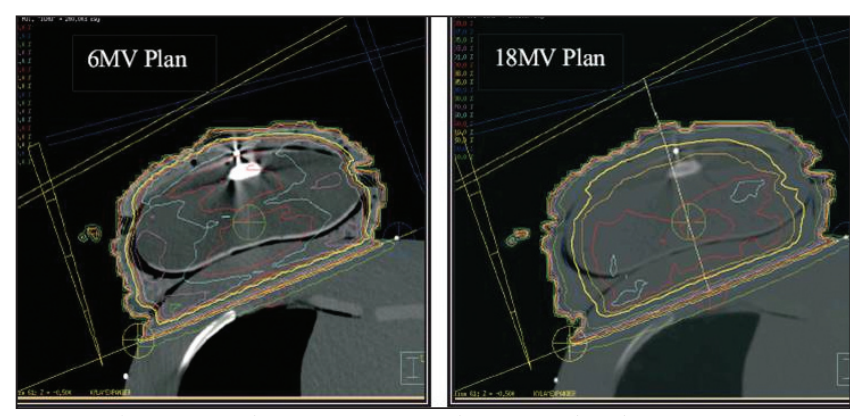

Figure 4) $6 \mathrm{MV}$ and $18 \mathrm{MV}$ computed tomography plans

the expander containing the port, eight TLDs were placed on the surface of the prostheses under the bolus, directly over and adjacent to the port (Figure 3). For comparison, eight TLDs were placed in the same location on the anterior surface of the saline-filled permanent implant. The Jeltrate phantom containing each of the prostheses, in turn, was then placed over the chest of a standard torso phantom. The permanent implants (saline and silicone) were computed tomography (CT) planned to receive $200 \mathrm{cGy}$ using standard tangent pairs of $6 \mathrm{MV}$ and $18 \mathrm{MV}$ photons (Figure 4). CT plans were used to calculate the expected dose for each TLD with each beam arrangement and energy.

Subsequently, each prosthesis was separately placed on the phantom torso and irradiated with a dose of 200 cGy using 6 MV and $18 \mathrm{MV}$ photon beams in an opposing tangential beam arrangement typical of true postmastectomy radiotherapy (Figure 5). With an additional $1.0 \mathrm{~cm}$ and $1.5 \mathrm{~cm}$ layer of superflab bolus material overlying the Jeltrate phantom, the expander with port and saline implant without port received $200 \mathrm{cGy}$ fractions using single direct $15 \mathrm{~cm} \times 15 \mathrm{~cm}$ electron fields of $9 \mathrm{MeV}$ and $12 \mathrm{MeV}$ electrons, respectively, to mimic boost radiotherapy. Each prosthesis was irradiated three times for three sets of TLD readings at each location around the prosthesis. Each time the prosthesis was irradiated new TLDs were used.

To examine the dosimetric effects of the metallic port, two-tailed $t$ tests were used to compare mean doses measured at each of the TLD positions near the port (Figure 3) with the mean dose measured at the corresponding TLD locations over the saline implant that contained no port. Comparisons were performed for $6 \mathrm{MV}$ photons, $18 \mathrm{MV}$ photons, $9 \mathrm{MeV}$ electrons and $12 \mathrm{MeV}$ electrons. To maximize the power of this comparison, measurements from multiple TLD positions from the three separate exposures were pooled to generate mean doses. Pooling of the TLDs also enabled easier comparison between the expected and delivered radiation doses. Pooling was appropriate 


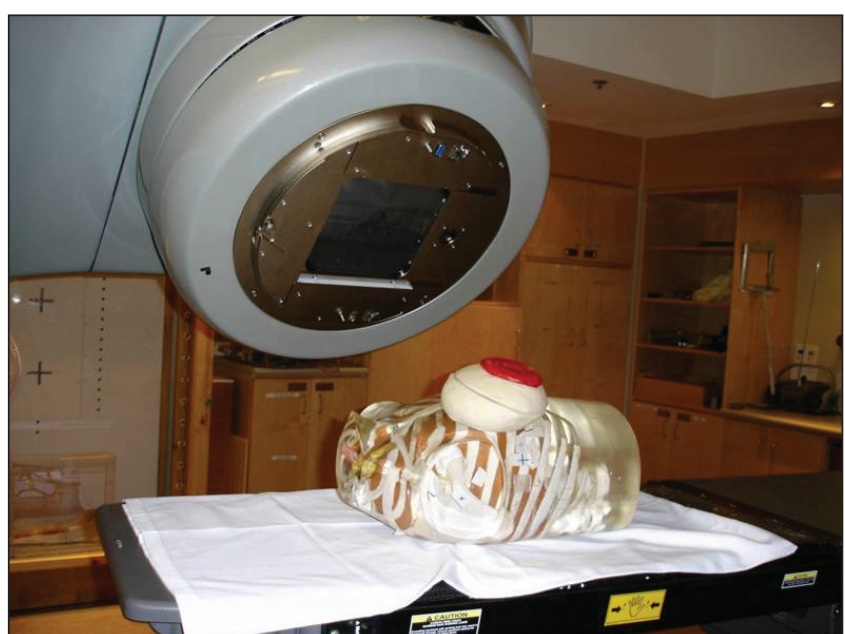

Figure 5) Irradiation of the phantom torso and prosthesis

because irradiation occurred as a single, direct beam; therefore, the amount of radiation received would be similar for all TLDs in that area. For $6 \mathrm{MV}$ and $18 \mathrm{MV}$ photons, measurements from five TLDs overlying the port were pooled as the mean doses 'over the port'. Two TLDs placed medial and lateral to the port were pooled as 'medial/ lateral to port' because the beam arrangement was a tangent pair and the radiation dose would be affected equally in the medial and lateral locations. Measurements from the TLD placed inferiorly were analyzed separately as 'inferior to port'. For the electron data, measurements from TLDs placed over the port were pooled as the mean dose 'over the port', and measurements from TLDs placed medial, lateral and inferior to the port were used to measure the mean dose 'adjacent to the port' because the electron beam was a single, direct beam and, therefore, would have affected the dose equally in each of these locations.

The dosimetric effects of the permanent silicone and saline implants were examined by comparing the measured dose from each TLD with the expected dose at the TLD location as calculated by the CT plan. Measurements from all three 200 cGy exposures were also pooled. In addition, measurements from adjacently positioned TLDs were pooled into eight location groups. Comparisons were performed for $6 \mathrm{MV}$ and $18 \mathrm{MV}$ photons. Expected doses for the silicone implant were also calculated using a heterogeneous plan that accounted for the differences in density between saline and silicone.

\section{RESULTS}

The dosimetric effect of the metallic port

There was no significant difference between the mean dose recorded by the TLDs placed directly over the metallic port and the related TLDs overlying the saline implant with no port $(P>0.05)$. Similarly, there was no significant difference between the mean dose received by TLDs adjacent to the site of the port and the corresponding TLDs on the saline implant $(P>0.05)$. Mean doses inferior to the port were also not significantly different compared with the saline implant $(\mathrm{P}>0.05)$ (Table 1).

Complementary results were found for the $9 \mathrm{MeV}$ and $12 \mathrm{MeV}$ electrons. There were no significant differences between the doses measured over and adjacent to the port on the Jeltrate phantom with expander and port and the corresponding doses from the saline implant breast without port $(\mathrm{P}>0.05)$ (Table 1$)$.

The dosimetric effect of permanent implants

The raw data indicated that in 22 of 24 TLD locations, there were no significant differences between the measured doses and the doses calculated from the CT plan around the permanent saline implant when using $6 \mathrm{MV}$ or $18 \mathrm{MV}$ photons ( $\mathrm{P}>0.05)$. However, when the measurements
TABLE 1

Mean radiation dose measured from the vicinity of the metallic port of the tissue expander, and corresponding locations over the non-port-containing permanent saline implant

\begin{tabular}{|c|c|c|c|}
\hline \multirow[b]{2}{*}{ Location } & \multicolumn{2}{|c|}{ Dose around, cGy } & \multirow[b]{2}{*}{$\mathrm{P}^{*}$} \\
\hline & $\begin{array}{c}\text { Tissue expander } \\
\text { with port }\end{array}$ & $\begin{array}{c}\text { Saline implant } \\
\text { without port }\end{array}$ & \\
\hline \multicolumn{4}{|l|}{$6 \mathrm{MV}$ photons } \\
\hline Over port & 208.2 & 210.4 & 0.61 \\
\hline Medial/lateral to port & 205.7 & 206.6 & 0.86 \\
\hline Inferior to port & 204.9 & 205.3 & 0.97 \\
\hline \multicolumn{4}{|l|}{$18 \mathrm{MV}$ photons } \\
\hline Over port & 211.0 & 205.9 & 0.33 \\
\hline Medial/lateral to port & 196.3 & 200.6 & 0.40 \\
\hline Inferior to port & 196.0 & 194.8 & 0.69 \\
\hline \multicolumn{4}{|l|}{$9 \mathrm{MeV}$ electrons } \\
\hline Over port & 190.6 & 188.3 & 0.57 \\
\hline Adjacent to port & 171.4 & 168.9 & 0.70 \\
\hline \multicolumn{4}{|l|}{$12 \mathrm{MeV}$ electrons } \\
\hline Over port & 190.1 & 188.5 & 0.64 \\
\hline Adjacent to port & 187.1 & 178.8 & 0.15 \\
\hline
\end{tabular}

*Two-sided $\mathrm{t}$ test

were pooled into location groups, no significant differences were found between the CT planned doses and the mean doses received by the saline implant $(\mathrm{P}>0.05)$ (Table 2).

When the silicone implant was used, the mean measured doses in several locations were significantly greater than the expected doses based on the CT plan $(\mathrm{P}<0.05$ ) (Table 2). Measured doses were $>15 \%$ higher than expected in five of the eight locations adjacent to the silicone implant. When a heterogeneous CT plan was used to calculate the expected doses, the results were similar with greater than expected dose measurements.

\section{DISCUSSION}

Previous studies investigating altered dosimetry around temporary expander ports have yielded conflicting results regarding the potential impact of the port on dose homogeneity during postmastectomy irradiation. Using TLD and film dosimeter measurements around a port that had been extracted from its implant, Moni et al (11) reported no significant alterations in dose. In 2005, Thompson and Morgan (12) used semiconductor diode measurements around a similar port in a water phantom with analogous geometry to demonstrate large reductions in dose behind the port. That study reported dose reductions of up to $23 \%$ at $10 \mathrm{~cm}$ beyond the port when the beam was directed parallel to the flat surface of the metallic disc. However, closer to the port, the dose normalized to within a few millimeters, regardless of whether the disc was being irradiated with the beam perpendicular or parallel to its surface. Using film dosimetry to assess dose variations in the shadow of the port in a water phantom with similar geometry to the other studies, Damast et al (13) reported dose reductions of up to $22 \%$ at $2.2 \mathrm{~cm}$ deep to the port. Again, dose perturbations lateral to the beam normalized within a short distance from the disc. The same study also performed film dosimetry and thermoluminescent dosimetry in vivo, measuring exit doses of medial and lateral tangent beams in postmastectomy patients receiving radiotherapy with a tissue expander in place. This study showed largely acceptable variations in skin dose, but some reduction in dose in the shadow of the expander.

The current study showed no significant dose variations over the port after standard tangent-beam irradiation using either $6 \mathrm{MV}$ or $18 \mathrm{MV}$ photons. This is likely because we irradiated the port while it remained in the expander so that dose variations near the port were contained within the substance of the expander itself rather than over the expander in what would be skin and subcutaneous tissue in the 
TABLE 2

Doses (cGy) received relative to expected dose calculated from CT plan for locations around the permanent implant

\begin{tabular}{|c|c|c|c|}
\hline \multirow[b]{3}{*}{ Location } & \multicolumn{3}{|c|}{ Implant } \\
\hline & \multirow[b]{2}{*}{ Saline } & \multicolumn{2}{|c|}{ Silicone } \\
\hline & & $\begin{array}{l}\text { Homogeneous } \\
\text { plan }\end{array}$ & $\begin{array}{c}\text { Heterogeneous } \\
\text { plan }\end{array}$ \\
\hline \multicolumn{4}{|l|}{$6 \mathrm{MV}$ photons } \\
\hline Anterior & $1.024 \pm 0.037$ & $1.117 \pm 0.029^{\star}$ & $1.125 \pm 0.029^{*}$ \\
\hline Antero-S/antero-I & $1.029 \pm 0.054$ & $1.117 \pm 0.033^{*}$ & $1.105 \pm 0.033^{\star}$ \\
\hline Anteromedial & $1.060 \pm 0.033$ & $1.167 \pm 0.013^{\star \star}$ & $1.160 \pm 0.012^{\star *}$ \\
\hline Anterolateral & $1.023 \pm 0.044$ & $1.118 \pm 0.031^{\star}$ & $1.100 \pm 0.030^{*}$ \\
\hline Posterior & $1.047 \pm 0.065$ & $1.055 \pm 0.028$ & $1.052 \pm 0.028$ \\
\hline Postero-S/postero-I & $1.020 \pm 0.039$ & $1.130 \pm 0.036^{*}$ & $1.113 \pm 0.036^{*}$ \\
\hline Posteromedial & $1.003 \pm 0.048$ & $1.122 \pm 0.025$ & $1.134 \pm 0.023$ \\
\hline Posterolateral & $1.013 \pm 0.033$ & $1.038 \pm 0.022$ & $1.031 \pm 0.023$ \\
\hline \multicolumn{4}{|l|}{$18 \mathrm{MV}$ photons } \\
\hline Anterior & $1.045 \pm 0.028$ & $1.166 \pm 0.015^{\star \star}$ & $1.169 \pm 90.015^{\star *}$ \\
\hline Antero-S/antero-I & $1.060 \pm 0.043$ & $1.201 \pm 0.031^{\star \star}$ & $1.179 \pm 0.031^{\star \star}$ \\
\hline Anteromedial & $1.073 \pm 0.052$ & $1.149 \pm 0.058^{\star}$ & $1.123 \pm 0.057$ \\
\hline Anterolateral & $1.043 \pm 0.046$ & $1.161 \pm 0.021^{\star \star}$ & $1.156 \pm 0.020^{\star \star}$ \\
\hline Posterior & $1.059 \pm 0.028$ & $1.089 \pm 0.086$ & $1.084 \pm 0.086$ \\
\hline Postero-S/postero-I & $1.038 \pm 0.069$ & $1.125 \pm 0.029^{*}$ & $1.137 \pm 0.030^{\star}$ \\
\hline Posteromedial & $1.037 \pm 0.020$ & $1.157 \pm 0.046^{\star}$ & $1.167 \pm 0.048^{\star}$ \\
\hline Posterolateral & $1.028 \pm 0.034$ & $1.110 \pm 0.052$ & $1.105 \pm 0.051$ \\
\hline
\end{tabular}

Data presented as mean $\pm S D$. ${ }^{*} 0.05>P>0.01 ;{ }^{*} 0.01>P>0.001$. Antero-I Anteroinferior; Antero-S Anterosuperior; CT Computed tomography; Postero-I Posteroinferior; Postero-S Posterosuperior

patient. We did not study dose variations in the shadow of the port where significant dose reductions may also occur; however, dosimetry as measured by TLDs placed posterior to the saline-filled expander and implant did not show significant reductions.

We also showed no significant dose variations over the port after irradiation using direct $9 \mathrm{MeV}$ or $12 \mathrm{MeV}$ electron beams. There are no previous studies examining the impact of the port on dose when electrons are used; however, one might expect an increase in dose anterior to the port when a direct electron beam is used as a result of increased backscatter from the titanium shell and the rare-earth magnet. Again, it is possible that inhomogeneities were present within the substance of the expander itself but did not reach as far as the TLD placed on top or behind the expander.

There was also no significant alteration in dose around the permanent saline implant compared with the doses calculated from the CT plan of the tangent fields. However, significant increases in dose in several locations around the permanent silicone implant were measured. The magnitude of these variations was large and certainly would be considered unacceptable in the context of radiation treatment planning. Dose variations around implants have not been previously reported, and it is not clear why silicone implants would affect dose in this manner. However, there is documented incidence of capsular contraction and reconstruction failure when permanent implants are irradiated; therefore, any increase in dose beyond the planned dose is of concern and certainly warrants further study. We have undertaken further study of the dosimetry around both saline and silicone implants using ion-chamber and film dosimetry with these implants in a water-bath phantom.

The results of our studies suggest that women who are reconstructed immediately with a saline-filled expander or implant can undergo radiation postoperatively without compromise or augmentation to the dose of radiation received in the surrounding soft tissues.

\section{CONCLUSION}

The metal port contained in a standard postmastectomy tissue expander does not appear to alter radiation dose to the adjacent tissue when standard photons or electrons are used. The presence of a saline implant does not appear to alter the radiation dose to the adjacent tissue. However, the dose delivered adjacent to a silicone implant is higher than expected for certain locations recorded in the present study, which may have implications for toxicity and reconstruction failure; however, to date, this finding is not upheld with further investigations. The results of our study strongly suggest that women who are reconstructed immediately with a saline-filled expander or implant can undergo radiation postoperatively without compromise or augmentation of the dose of radiation received in the surrounding soft tissues.

ACKNOWLEDGEMENTS: The authors thank Kaitlyn Whelan for her assistance on this project.

AUTHOR CONTRIBUTIONS: Arianna Dal Cin: Creation of study design, data collection, and authorship and editing of manuscript; Barbara Strang: Creation of study design, data collection and authorship and editing of manuscript; Kyla Murphy: Creation of study design, data collection and authorship and editing of manuscript; Shane Seal: Creation of study design, data collection and authorship and editing of manuscript. Special Acknowledgement: Katelyn Whelan: preparation of the manuscript.

DISCLOSURES: The authors have no financial disclosures or conflicts of interest to declare.

\section{REFERENCES}

1. Canadian Cancer Society's Steering Committee: Canadian Cancer Statistics 2009. Toronto: Canadian Cancer Society, 2009.

2. Post-mastectomy radiotherapy: Clinical practice guidelines of the American Society of Clinical Oncology. J Clin Oncol 2001;19:1539-69.

3. Truong PT, Olivotto IA, Whelan TJ, et al. Clinical practice guidelines for the care and treatment of breast cancer: 16 . Locoregional postmastectomy radiotherapy. CMAJ 2004;170:1263-73.

4. Ragaz J, Jackson SM, Le N, et al. Adjuvant radiotherapy and chemotherapy in node-positive premenopausal women with breast cancer. N Engl J Med 1997;337:956-62.

5. Overgaard M, Hansen PS, Overgaard J, et al. Postoperative radiotherapy in high-risk premenopausal women with breast cancer who receive adjuvant chemotherapy. Danish breast cancer cooperative group 82b trial. N Engl J Med 1997;337:949-55.

6. Overgaard M, Jensen MB, Overgaard J, et al. Postoperative radiotherapy in high-risk postmenopausal breast-cancer patients given adjuvant tamoxifen: Danish breast cancer cooperative group DBCG 82c randomized trial. Lancet 1999;353:1641-8.

7. Recht A, Edge SB, Lawrence JS, et al. Postmastectomy radiotherapy: Guidelines of the American Society of Clinical Oncology. J Clin Oncol 2001;10:1539-69.

8. Overgaard M, Nielson HM, Overgaard J. Is the benefit of postmastectomy irradiation limited to patients with four or more positive nodes, as recommended in international consensus reports? A subgroup analysis of the DBCG 82 b\&c randomized trials. Radiother Oncol 2007;82:247-53.

9. Babic S, Kerr AT, Westerland M, Gooding J, Schreiner LJ. Examination of Jeltrate-Plus as a tissue equivalent bolus material. J Appl Clin Med Phys 2002;3:170-5.

10. Measurement of Absorbed Dose. Thermoluminescent Dosimetry. In: Measurement of Absorbed Dose, Khan F. The Physics of Radiation Therapy, 4th edn, Baltimore: Lippincott Williams \& Wilkins, 2009;127.

11. Moni J, Graves-Ditman M, Cederna P, et al. Dosimetry around metallic ports in tissue expanders in patients receiving postmastectomy radiation therapy: An ex vivo evaluation. Med Dosim 2004;29:49-54.

12. Thompson RCA, Morgan AM, Investigation into dosimetric effect of a MAGNA-SITETM tissue expander on post-mastectomy radiotherapy. Med Phys 2005;32:1640-6.

13. Damast S, Beal K, Ballangrud A, et al. Do metallic ports in tissue expanders affect postmastectomy radiation delivery? Int J Radiat Oncol Biol Phys 2006;66:305-10. 